\title{
Mapas mentais: técnica de memorização e estudo para o voo no 2 Esquadrão de Instrução Aérea
}

\author{
Mind maps: study and memorization technique for the flight in the $2^{\text {nd }}$ Air \\ Instruction Squadron
}

Mapas mentales: técnica de memorización y estudio para el vuelo en el 2o Escuadrón de Instrucción Aérea

Cad Av Roberto Renato Lima da Silva Academia da Força Aérea - AFA Pirassununga/SP - Brasil renato.ret06@gmail.com

$1^{\circ}$ Ten Adm Simon Skarabone Rodrigues Chiacchio, Doutor Instituto de Logística da Aeronáutica - ILA São Paulo/SP - Brasil professorsimon@ig.com.br

$1^{\circ}$ Ten Mfs Bruno Eduardo Teixeira, Mestre Academia da Força Aérea - AFA Pirassununga/ SP- Brasil br_edu@hotmail.com

Adriano Rogério Bruno Tech, Doutor Faculdade de Zootecnia e Engenharia de Alimentos - FZEA Pirassununga/SP - Brasil adriano.tech@usp.br

\section{RESUMO}

O curso de pilotagem militar, ministrado no $2^{\circ}$ ano da Academia da Força Aérea (AFA), pode ser considerado um curso com o nível elevadíssimo de exigência relacionada à preparação teórica e, nesse caso, torna-se viável o uso de métodos de estudos variados. A proposta deste trabalho é apresentar aos cadetes aviadores os mapas mentais, descrevendo por meio deles algumas passagens dos manuais de voo e estimulando seu uso no âmbito do Corpo de Cadetes. Acredita-se que a técnica atende ao tipo de estudo que o voo solicita, com muita informação a ser memorizada e, sendo assim, poderia-se ter na AFA um número menor de desligamentos em voo. Para atingir os objetivos foram realizadas pesquisas bibliográficas e pesquisa com os cadetes acerca dos mapas mentais. Os resultados mostraram-se positivos para a aplicação e uso dos mapas mentais nas atividades de estudo para a instrução aérea.

Palavras-chave: Mapas mentais. $2^{\circ}$ Esquadrão de Instrução Aérea. Instrução aérea. Aviação militar.

Recebido / Received / Recibido $22 / 11 / 14$
Aceito / Accepted / Aceptado

30/05/15 


\section{ABSTRACT}

The military piloting course, taught in the $2^{\text {nd }}$ year of the Air Force Academy (AFA), can be considered a course with a very high level of requirement related to theoretical preparation, and in this case, the use of various research methods is feasible. The purpose of this paper is to present the mental maps to aviator cadets, describing through them a few passages from the flight manuals and to encourage their use within the Cadet Corps. It is believed that this technique serves the type of study that the flight calls, with much information being memorized, in order, there could be fewer students' dismissals in flight at AFA. To achieve the goals, literature searches and surveys about mental maps were conducted among the cadets. The results turned out to be positive for the application and use of mind maps in the study activities for air instruction.

Keywords: Mind maps. $2^{\text {nd }}$ Air Instruction Squadron. Air instruction. Military aviation.

\section{RESUMEN}

El curso de piloto militar, dictado en el $2^{\circ}$ año de la Academia de la Fuerza Aérea (AFA), puede ser considerado un curso de elevadísimo de exigencia relacionada a la preparación teórica y, en este caso, se vuelve factible el uso de métodos de estudios variados. La propuesta de este trabajo es presentar a los cadetes aviadores los mapas mentales, describiendo por medio de ellos algunos pasajes de los manuales de vuelo y estimulando su uso en el ámbito del Cuerpo de Cadetes. Se acredita que la técnica cumple con el tipo de estudio que el vuelo solicita, con mucha información a ser memorizada y, siendo así, se podría tener en la AFA un número menor de desconexiones en vuelo. Para alcanzar los objetivos se realizaron búsquedas bibliográficas y encuestas con los cadetes acerca de los mapas mentales. Los resultados se mostraron positivos para la aplicación y uso de los mapas mentales en las actividades de estudio para la instrucción aérea.

Palabras clave: Mapas mentales. $2^{\circ}$ Escuadrón de Instrucción Aérea. Instrucción aérea. Aviación militar.

\section{INTRODUÇÃO}

Ser piloto de aeronaves, seja de caça, de transporte ou de asas rotativas, representa o sonho de voar de muitos jovens e crianças. Motivados, talvez, pela esquadrilha da fumaça, com suas apresentações aéreas, ou pelo incentivo de um aviador na família, ou apenas pela missão exercida, muitos estabelecem o objetivo de ingressar na Força Aérea Brasileira (FAB) para servirem à Pátria como pilotos militares.

A Academia da Força Aérea (AFA) é uma instituição de ensino superior da FAB, que tem por objetivo formar os futuros líderes da Força Aérea, ministrando os cursos de aviação, intendência e infantaria. O aprendiz da AFA tem o posto de Cadete e, ao seguir carreira, poderá chegar ao posto militar mais elevado: o de Oficial-General.

O curso de pilotagem militar para os cadetes aviadores é dividido em instrução básica, ministrado no $2^{\circ}$ Esquadrão de Instrução Aérea ( $2^{\circ}$ EIA), no $2^{\circ}$ ano de formação, com a aeronave T-25 Universal; e instrução avançada, ministrado pelo $1^{\circ}$ Esquadrão de Instrução Aérea (1ํㅡㄹ EIA), no 4ํano, com a aeronave T-27 Tucano.

O que muitos candidatos desconhecem é que a formação do piloto militar é repleta de exigências que podem implicar sérias dificuldades, sejam elas técnicas, operacionais, psicomotoras ou psicológicas. O índice dos que não concluem o curso de pilotagem no $2^{ }$EIA fica em torno de $30 \%$ de perda de recursos humanos.

Esse enorme contingente de pessoas excluídas no processo de formação acaba impactando negativamente naqueles que devem passar pela instrução de voo. Sendo assim, eles investem muito tempo em dedicação aos estudos, na maioria dos casos, durante as próprias férias ao final do $1^{\circ}$ ano. Geralmente, como técnica de estudo, costumam fazer cópias dos manuais, resumos, desenhos, esquemas e simulações, para que esses materiais sirvam de instrumento de estudo para os mais diferentes desafios no preparo e estudo às diferentes disciplinas. A pergunta que surge é: será que esses métodos de estudo são os mais eficientes?

\section{O $2^{\circ}$ ESQUADRÃO DE INSTRUÇÃO AÉREA}

\section{$2.1 \mathrm{O}$ estudo para o voo}

É necessário entender que, por ser uma profissão de risco, a aviação requer muita dedicação aos estudos. O termo "profissão de risco", nesse contexto, refere-se ao risco de morte, inerente à própria atividade aérea em determinadas situações - as de pouso e decolagem, por exemplo, nas quais é maior o índice de acidentes. 
Nesses momentos, exige-se muito da capacidade multitarefa do piloto, e o processo decisório pode ser comprometido, se o profissional tiver sua concentração dividida entre as tarefas psicomotoras e os procedimentos normais.

Um dos fatos que diferencia o curso de pilotagem civil do curso militar é que, no meio civil, se o aluno não atingir o desempenho esperado em uma missão de avaliação, incidirá o transtorno de pagar quantas aulas de revisão considerar necessárias e refazê-las. No âmbito militar, devido à limitação de horas de voo disponíveis para a instrução, o cadete que não atinge o nível esperado, em um certo número de missões, pode ser desligado da Academia.

Pode-se dizer que o estudo para o voo envolve 4 (quatro) esferas de atividades: decorar os procedimentos de emergência (as "panes"), decorar os procedimentos normais (os "cheques"), estudar o Manual de Instrução Técnica da aeronave T-25 (MAITE) e estudar o Manual de Procedimentos (MAPRO).

Toda aeronave possui um checklist, livreto em que são indicados todos os procedimentos normais e de emergência correspondentes. Os procedimentos de emergência (as chamadas "panes"), no total 29 (vinte e nove), indicam a sequência de medidas a serem tomadas no caso de alguma situação de emergência em voo, por exemplos: falha do motor em voo, fogo na asa, fogo no motor na partida, etc. São ações que podem salvar a vida do piloto no caso de um imprevisto.

Decorar e saber cotejar com fluência todas as panes é uma parte do estudo para o voo, que geralmente é escolhido como primeiro passo. Os cadetes costumam fazer isso no segundo semestre do $1^{\circ}$ ano, por volta de agosto ou setembro. Para facilitar o processo, a turma confecciona os "pane-cards", que são 29 (vinte e nove) cartões plastificados, cada um com uma pane impressa. A vantagem é poder carregá-los no bolso, coisa que não pode ser feita com o checklist, e estudar a qualquer momento em que haja tempo ocioso.

Há também quem faça cópias, para memorizar os procedimentos normais. Geralmente, os cadetes fazem a leitura repetida daqueles até conseguirem cotejá-los sem consulta.

\subsection{Manual de Instrução Técnica (MAITE)}

No decorrer dos últimos meses do ano, nos meses de setembro ou outubro, o próprio cadete do $1^{\circ}$ ano confecciona uma cópia do Manual de Instrução Técnica, pois a seção de instrução só o fornece em novembro.

No MAITE, encontram-se as informações acerca dos sistemas, dos limites de operação e das características de voo da aeronave T-25. É o manual que permite conhecê-la a fundo, pois é repleto de informações e números que devem ser memorizados.

A instrução do MAITE é dada à aviação do $1^{\circ}$ esquadrão por instrutores de voo do $2^{\circ}$ EIA na disciplina "Instrução Técnica da Aeronave T-25" (ITA-5), ministrada em novembro.

A avaliação da disciplina é feita no início do ano seguinte, o que permite que os cadetes estudem durante as férias. A prova é composta por 50 (cinquenta) questões objetivas, em que poucos erram mais de duas dessas questões.

O Gráfico 1 mostra as médias das turmas dos últimos 5 (cinco) anos em ITA-5 e em Direito Geral, disciplina ministrada para toda a turma durante o $1^{\circ}$ ano, tomada como exemplo para fins comparativos das disciplinas em relação à disciplina do campo específico de aviação.

Gráfico 1 - Médias gerais em ITA-5 e Direito Geral nos últimos 5 anos.

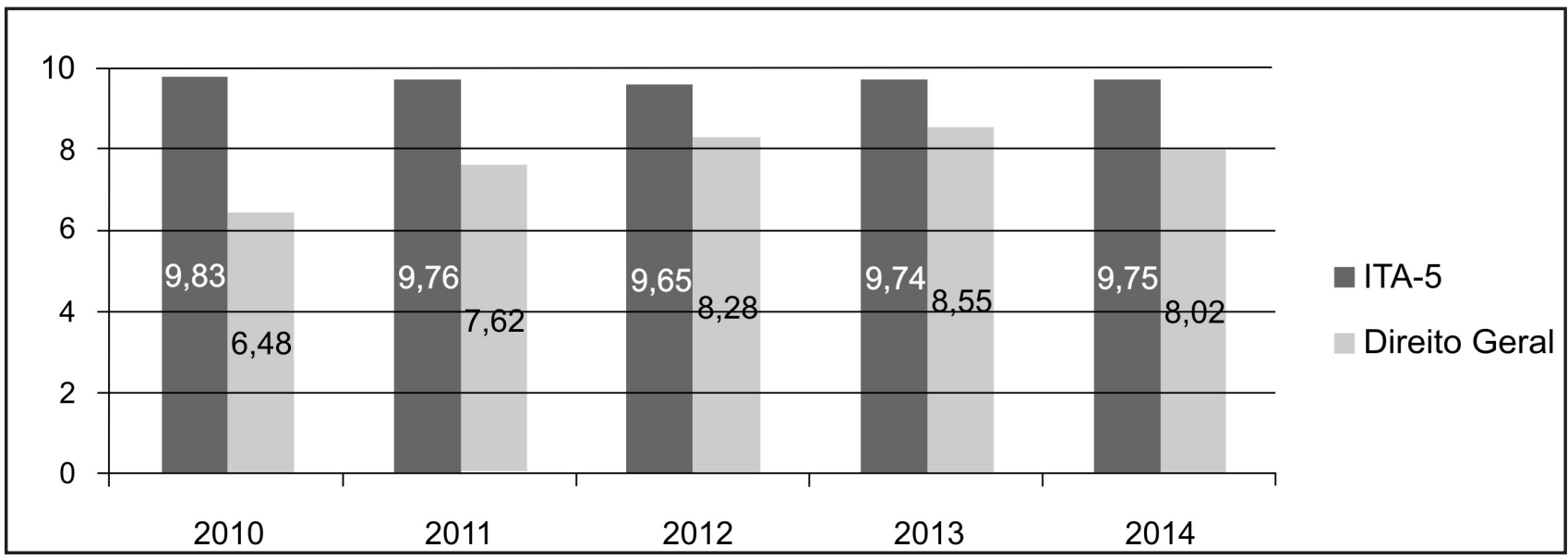

Fonte: $\mathrm{O}$ autor. 


\subsection{Manual de Procedimentos (MAPRO)}

Todas as regras e padronizações que dizem respeito ao voo no setor $\mathrm{E}$ (Leste) da Academia, onde é realizado o voo do $2^{\circ}$ EIA, está contido no Manual de Procedimentos.

Ao início do $2^{ }$ano, os aviadores têm o Apronto da Fase de Pré-Solo, uma aula para toda a aviação, em que as regras contidas no MAPRO são expostas e os exercícios de pilotagem da fase são padronizados. $\mathrm{O}$ apronto também é avaliado pela chamada "prova do MAPRO”, realizada pouco depois da avaliação de ITA-5.

Para iniciar o voo, o cadete deve memorizar bem os procedimentos normais contidos no checklist (ex.: partida do motor, inspeção interna, subida, etc.), simulando sua execução dentro do avião. Simular repetidas vezes a sequência de passos dos procedimentos previstos para o voo dentro da aeronave, com a bateria desconectada, é o que se chama de "fazer horas de nacele". Com a realização da nacele, a fixação da informação é melhorada e o aprendizado é mais eficaz.

As aeronaves T-25 do pátio do $2^{\circ}$ EIA são disponibilizadas para estudo de cadetes do $1 \stackrel{0}{\circ}$ ano a partir de novembro. Ao final de outubro, são atribuídas as funções de "líder de nacele" aos cadetes aviadores do $2^{\circ}$ ano que já concluíram o curso e são incumbidos de praticar horas de nacele além de tirar dúvidas de, geralmente, dois ou três liderados do $1^{\circ}$ ano. Quando o liderado aprende a simular os cheques no avião, torna-se comum que se dirijam ao pátio e façam, sozinhos ou acompanhados de colegas, horas do exercício.

O Comandante do Corpo de Cadetes da Aeronáutica (CCAer), autoriza que, iniciadas as férias, eles permaneçam na AFA por até uma semana e retornem delas uma semana mais cedo para fazerem nacele. Com o intuito de praticarem durante as férias, há quem se desloque, também, para outras unidades da FAB que operam o T-25, como a Escola de Especialistas de Aeronáutica (Guaratinguetá-SP) e o Parque de Material Aeronáutico de Lagoa Santa (Lagoa Santa-MG).

Outra forma de fixar os cheques, muito usada nos próprios alojamentos e durante as férias, é a chamada "fotocele", uma foto com impressão em grandes dimensões (80x60 cm ou mais) do painel da aeronave, como forma de se acostumar com as posições dos indicadores e simular os procedimentos.

Além de líderes de nacele, aos veteranos do $2^{\circ}$ ano também é delegada a função de ministrar as chamadas

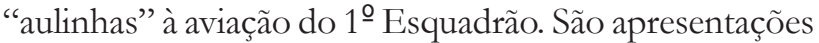
informais, que antecedem as instruções de ITA-5 e abordam, geralmente, um capítulo do MAITE por dia, com o intuito de explicar-se o manual e tirar dúvidas.

\subsection{Cheque de olhos vendados e prova de emergências (CHOVE)}

O estudo durante as férias é um revezamento entre o MAITE, revisões constantes das panes, aprendizado e fixação dos cheques, estudo do MAPRO e realização de horas de nacele.

Boa parte dos cadetes estuda, pelo menos, algumas horas por semana durante as férias, dividindo o tempo entre a família, o lazer e o estudo para o voo. Os principais métodos de aprendizado são cópias, resumos, resolução de questionários e releituras frequentes dos manuais.

Depois de retornar das férias, em janeiro, e fazer as avaliações de ITA-5 e do apronto, em fevereiro, o cadete do $2^{\underline{0}}$ ano passa ainda pela Prova de Emergências Críticas e pelo Cheque de Olhos Vendados (CHOVE). A prova consiste de uma pequena avaliação do conhecimento das panes mais importantes, enquanto o CHOVE é uma atividade na qual o cadete, de olhos vendados dentro do avião, deve indicar para um instrutor de voo a posição correspondente dos itens que ele perguntar. É uma forma de avaliar a familiarização do cadete com a nacele.

\subsection{Avaliações}

Geralmente o curso de pilotagem do $2^{0}$ ano (estágio básico de T-25) não dura mais de sete meses. No ano de 2013, iniciou-se no final de fevereiro e terminou em setembro, depois que o último cadete finalizou a fase de navegação. Cada cadete conclui com aproximadamente 45 horas de voo.

Nos aeroclubes, o voo de cheque é realizado após, pelo menos, 17 horas de instrução, conforme prevê o Manual do Comando da Aeronáutica 58-3 (Manual do Curso Piloto Privado de Avião). Se obtiver resultado desfavorável no cheque, o aluno poderá pagar quantas aulas de revisão considerar necessárias e refazê-lo quando estiver pronto. Ou seja, o aluno civil pode acabar a fase de pré-solo com 20 horas, que é o mínimo exigido pelo manual, ou bem mais, dependendo de seu rendimento.

O conhecimento teórico é extremamente cobrado, principalmente nas primeiras semanas de instrução. $\mathrm{O}$ cadete que não atinge esse critério, visivelmente, destacase do grupo diante das avaliações, sejam elas por meio de perguntas feitas por instrutores antes e depois de missões ou através de provas surpresas aplicadas, cuja resolução geralmente tem o tempo limitado de 15 minutos.

A taxa de atrito dos últimos anos, quando comparada com outras academias militares, é alta. No Gráfico 2 é possível verificar uma comparação entre as taxas de atrito (percentual de aspirantes que não concluíram o curso) dos últimos três anos no $2^{\circ}$ EIA. 
Gráfico 2 - Taxas de atrito no estágio básico T-25 nos últimos 3 anos.

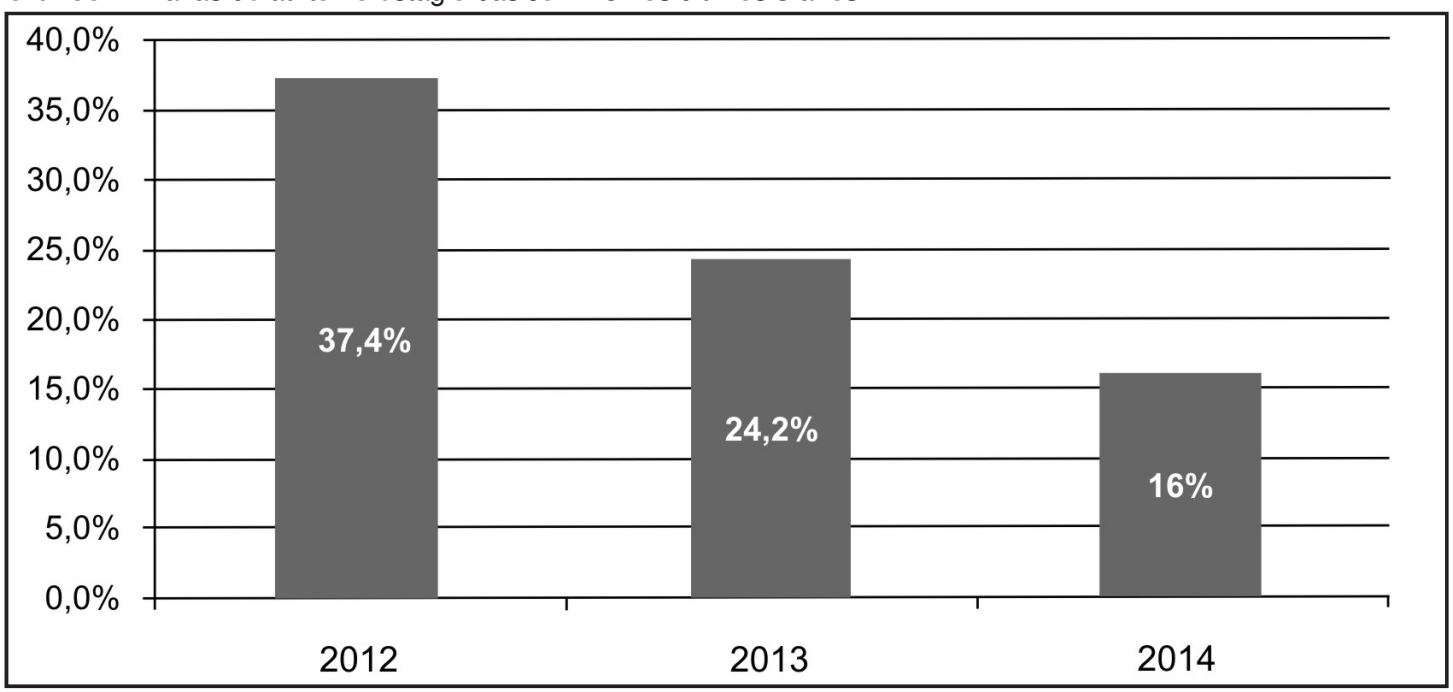

Fonte: $\mathrm{O}$ autor.

O Programa de Instrução e Manutenção Operacional (PIMO) estabelece que, se o aluno obtiver grau 2 (dois) em um ou mais itens da avaliação do voo (que são 45 (quarenta e cinco) no cheque do Pré-Solo, por exemplo), à missão será atribuído grau 2 (dois) (deficiente).

Se 4 (quatro) desses itens estão presentes em todas as missões do curso e dizem respeito somente à preparação teórica (Conhecimento teórico, Conhecimento dos procedimentos de emergência, Aplicação de NPA e Inspeções e Cheques), é importante que o cadete saiba prontamente o conteúdo teórico que diz respeito ao voo até o final do curso.

Além disso, memorizar a execução dos exercícios realizados nas 4 (quatro) fases, com todas as suas características e peculiaridades, carece de muito estudo e de muitas horas de nacele.

É esperado que o aluno, à medida que avança no EIA e aprende exercícios novos, mantenha-se em revisões do MAITE e das panes, para que se mantenha atualizado nos itens de avaliação de conhecimento teórico.

Percebe-se, nesse contexto, a questão de aprendizagem e também da rotina do cadete sobre grande influência no que diz respeito à necessidade de se utilizar um procedimento eficiente para os estudos dos procedimentos técnicos das instruções, fator que justificou a pesquisa para verificar os métodos mais eficientes na aprendizagem do cadete aviador.

\section{PROPOSTAS EDUCACIONAIS}

Na década de 1970, o inglês Tony Buzan desenvolveu em Londres o diagrama chamado "mapa mental". Segundo o criador, o mapa estimula e auxilia a mente na memorização e organização de informações, tendo por base estímulos visuais e associações que imitam a estrutura do pensamento.
Compreende-se que os mapas mentais podem ajudar em "um caminho mais curto" para que se atinja a proficiência nos estudos que o voo solicita, pois estimula a memorização e proporciona revisões mais rápidas.

Além disso, há também possíveis aplicações dos mapas em passagens dos manuais de voo e estímulo, de maneira geral, de seu uso por parte dos futuros oficiais da Força Aérea Brasileira.

A viabilidade da técnica se baseia na hipótese de que ela atende ao tipo de estudo que o $2^{\circ}$ EIA solicita, repleto de informações a serem memorizadas.

Segundo Buzan, A natureza dos Mapas Mentais está intimamente
relacionada ao funcionamento da mente. Assim,
eles podem ser usados em praticamente todas as
atividades que envolvem pensamento, memorização,
planejamento ou criatividade. (BUZAN, 2010, p. 150).

Assim sendo, acredita-se também que a ferramenta possa amparar indivíduos que julgam ter dificuldades para guardar informações técnicas. Em sua obra, o autor destaca a importância da revisão, deixando claras as vantagens de revisar versus as desvantagens de não revisar (BUZAN, 2010).

\subsection{Mapas mentais}

No final da década de 1960 e início de 1970, o neurobiólogo norte-americano Roger Sperry deu início a uma série de estudos a respeito do cérebro. Por seu trabalho sobre "o cérebro dividido", Sperry recebeu o prêmio Nobel de medicina em 1981, motivando uma série de pesquisas sobre a capacidade mental humana, que atingiram seu apogeu nos anos 1990, quando o senado norte-americano os declarou como "a década do cérebro".

Embora muito ainda se desconheça, houve, com os estudos daquela época até os dias de hoje, uma 
aproximação dos conhecimentos da capacidade cerebral humana. Reconhecer o potencial do cérebro é o ponto de partida para acreditar na eficácia dos mapas mentais. Os autores Ontoria, Luque e Gómez (2006, p. 13) exibem alguns números e analogias a respeito do cérebro:

- Número de neurônios: 30 (trinta) ou 100 (cem) bilhões maior que o número de estrelas da Via-Láctea.

- Conexões neuronais: cada célula nervosa possui entre 1000 (mil) e 500000 (quinhentas mil) conexões. Isso significa que o número possível de conexões no cérebro é astronômico: $25 \times 10^{30}$.

- A National Academy of Sciences faz a seguinte estimativa: um só cérebro humano tem um número maior de conexões possíveis entre suas células nervosas que o número total de partículas atômicas existentes no universo.

- O cérebro seria equivalente a um computador com 20 (vinte) milhões de livros de 500 (quinhentas) páginas cada um.

- Se recebêssemos 10 (dez) unidades (palavra/imagem) por segundo, durante 10 (dez) anos, não teríamos utilizado nem $1 / 10$ da capacidade de armazenamento do cérebro.

Tais informações, embora não tenham relevância direta com o uso de mapas mentais, segundo os autores, representam o potencial ilimitado da mente humana. Saber que o próprio cérebro é capaz de realizar tarefas inimagináveis e reter grande quantidade de informações é algo que pode motivar estudantes que julgam ter dificuldades no aprendizado.

Os estudos de Sperry (1970) e sua equipe de pesquisa demonstraram que há uma lateralidade das funções cerebrais. Os hemisférios direito e esquerdo do cérebro são responsáveis por habilidades específicas que determinam o modo de pensar, a percepção e a personalidade dos indivíduos. Sua pesquisa foi o ponto de partida que multiplicou os estudos nessa área.

De acordo com Buzan (2010) o hemisfério esquerdo está vinculado à questão relacionada a lógica, palavras, listagens, números, relações, linearidade, análise e ações do gênero - as atividades consideradas acadêmicas. Ele determina um pensamento analítico e racional, orientado pela lógica. Pessoas que usam o hemisfério esquerdo de forma predominante tendem a ser racionais, minuciosas, perfeccionistas e precisam de um ambiente de trabalho organizado, sem elementos de dispersão.

O hemisfério direito está ligado à imaginação, cores, ritmos, percepção espacial, visualização e criatividade.

Segundo Ontoria, Gómez e Molina (1999 apud ONTORIA; LUQUE; GÓMEZ, 2006, p. 16-17) "é mais orientado ao todo do que à diferenciação das partes; e ainda à integração e à síntese do que à decomposição e análise."

O hemisfério esquerdo desenvolve capacidade lógica, organização, na tomada de decisão, tendendo a se basear mais no dado real que na intuição.
De acordo com Ontoria, Luque e Gómez (2006), na cultura ocidental, a educação vinha valorizando o hemisfério esquerdo em detrimento do direito, ou seja, o pensamento racional, analítico, sequencial e linguístico.

Atualmente as habilidades características do hemisfério direito vêm sendo reconhecidas por estudiosos e acreditase que, para o aprendizado ser total, devem-se usar as duas metades em conjunto e deve haver uma complementação das funções cerebrais, para consolidar um pensamento mais completo.

A unidade básica do sistema nervoso é o neurônio, célula formada por um núcleo e por inúmeros dendritos (um deles mais longo, chamado axônio), que são prolongamentos por meio dos quais há conexões com outros neurônios. O processo de interação entre eles é chamado sinapse (Figura 1). Segundo Lent,

\begin{abstract}
A sinapse é a unidade processadora de sinais do sistema nervoso. Trata-se da estrutura microscópica de contato entre um neurônio e outra célula, através da qual se dá a transmissão de mensagens entre as duas. (LENT, 2001, p. 112).
\end{abstract}

De acordo com Ontoria, Luque e Gómez (2006, p. 14), cada célula nervosa pode efetuar mais de 10000 (dez mil) conexões por segundo.

Figura 1 - Ilustração de transmissão sináptica entre células nervosas.

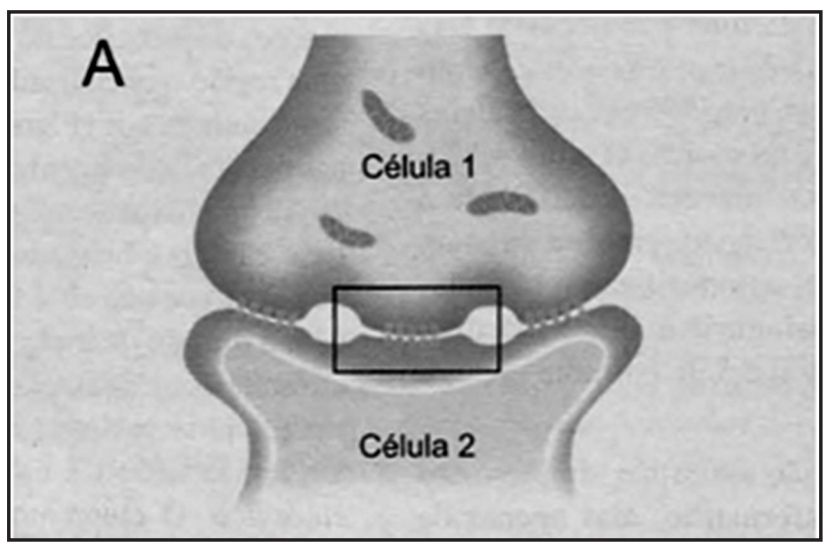

Fonte: Lent (2001, p. 115).

No aprendizado, o cérebro age a partir de associações (ONTORIA; LUQUE; GÓMEZ, 2006, p. 23). Quando uma unidade de informação (uma imagem, um dado, um sabor de alimento, por exemplo) chega ao cérebro, imediatamente são geradas conexões com outros dados disponíveis. "O número de conexões sinápticas ligadas a uma informação específica determina a qualidade de sua retenção" (BUZAN, 2010, p. 34). Isso quer dizer que, quanto mais conexões simultâneas existirem, quando um indivíduo armazena algo em sua mente, maior é a probabilidade de que se lembre dela depois.

A criação de associações com a informação disponível é uma das perspectivas a partir das quais os autores 
Ontoria, Luque e Gómez (2006) definem o significado da expressão "pensamento irradiante". A palavra "irradiante" aqui se interpreta a partir da analogia da estrutura de associações do pensamento com uma esfera central acesa, cuja luz se "irradia" para diferentes direções.

\subsection{Mnemônicos}

Mnemônicos ${ }^{1}$, sejam palavras, canções, imagens, esquemas, frases, etc., são artifícios utilizados para a recuperação de informações na memória. É uma técnica conhecida, praticada e constantemente usada por alunos dos ensinos médio e superior, inclusive por cadetes na AFA, sobretudo por aviadores nas fases de voo.

Músicas que remetem a fórmulas matemáticas ou frases que indicam os elementos da tabela periódica, por exemplo, são poderosos mnemônicos usados por vestibulandos. O famoso esquema que representa os meses que têm 31 (trinta e um) dias nos ossos das mãos também se enquadra nessa técnica. Tony Buzan (2010, p. 74) diz que ela é um poderoso meio de estimular a imaginação e encorajar o cérebro a fazer associações.

Usar mnemônicos é um hábito que deve ser explorado no processo de memorização, especialmente por parte de cadetes aviadores da AFA. Costuma-se, no estudo de manuais de voo, utilizar acrônimos, que são palavras formadas pelas primeiras letras ou sílabas de palavras sucessivas de uma locução (exemplo: ONU, Organização das Nações Unidas).

Recomenda-se que o desenvolvimento desses "estimuladores da memória" vá além da construção de acrônimos. Pode-se criar uma infinidade de "imagenschave" ou de canções, por exemplo, como formas eficientes de resgatar informações na memória. Buzan (2010, p. 76) afirma que mnemônicos que façam apelo a mais de um sentido corporal são mais poderosos. Por exemplo, uma lembrança que contenha cheiro, textura e som, é mais bem assimilada que outra que contenha somente imagens.

Nesse contexto, segundo o mesmo autor, tudo que seja representado por meio de movimento, sexualidade, humor, números, simbolismo e exagero, entre outros, terá mais potencial de fixar informações na memória (BUZAN, 2010, p. 76-80). Dessa forma, desenvolver mnemônicos com essas características acaba sendo uma boa estratégia para gravar informações.

\subsection{Palavras-chave}

Nas atividades de estudo, é importante que se desenvolva a capacidade de resumir parágrafos eideias gerais em palavras-chave. $\mathrm{O}$ uso delas permite que se gaste menos tempo na retenção de informações e que se façam revisões mais eficientes. Segundo Buzan (2010, p. 116), haveria dois tipos de palavras-chave: as de memorização e as criativas.

Palavras-chave criativas são evocativas. Elas tendem a formar imagens diversas na mente, não levando a um caminho específico de pensamento. Uma palavra-chave criativa é mais "geral", pode estimular interpretações distintas em pessoas diferentes. Usando o exemplo do autor, 'palavras como 'destilar' e 'bizarro' são especialmente evocativas, mas não necessariamente trazem à mente uma imagem específica" (BUZAN, 2010, p. 116).

As palavras-chave de memorização, por sua vez, são aquelas que forçam a mente a fazer as ligações adequadas na direção correta. Elas carregam dentro de si uma vasta gama de imagens e, ao serem resgatadas, trazem da memória as mesmas imagens. Tendem a ser um substantivo expressivo ou um verbo, rodeados por adjetivos ou advérbios-chave secundários.

Durante os estudos, deve-se tomar o cuidado de sempre adotar palavras-chave eficientes, ou seja, de memorização. A escolha de palavras-chave criativas pode abrir espaço para interpretações incorretas, por dois motivos, segundo Buzan (2010, p. 116):

- Natureza multiordenada das palavras: uma palavra precisa se conectar a outras para gerar ideias e pode apresentar mais de um significado, quando usada em contextos distintos. Por exemplo, a palavra "bala" nas frases: "a criança chupou bala de morango" e "na autópsia, foi encontrada uma bala no coração".

- Diferenças entre experiências e personalidade das pessoas: a mesma palavra pode gerar conexões diferentes na mente de indivíduos distintos, na medida em que eles se diferenciam em sua vivência de mundo e personalidade. A palavra "agulha", por exemplo, pode despertar em uma criança lembranças ruins, como a dor que sentiu ao ser vacinada. A uma costureira, porém, provavelmente irá trazer imagens de sua rotina de trabalho, podendo fazê-la lembrar-se de um serviço que terá de concluir.

Ainda segundo Buzan,

A parte principal da memorização está na natureza do conceito-chave. Não é, como normalmente se acredita, um processo verbal de palavra a palavra. (BUZAN, 2010, p. 118).

Devido à fala e à escrita, modo que o locutor adota para transmitir as imagens que tem na mente, hoje se tem a crença errônea de que o melhor modo de se lembrar de imagens e ideias é por meio de frases. Dessa forma, os discentes nas escolas gastam muito tempo fazendo longas anotações das aulas que, na prática, conforme experiência do próprio Buzan, são ineficientes. O

\footnotetext{
${ }^{1}$ Origem etimológica: do grego mneme, que significa "memória" e mnemon, que significa "cônscio, ciente". Ressalte-se que Mnemosine era
} a deusa grega da memória. 
autor defende que $90 \%$ das palavras utilizadas em uma tradicional anotação escolar não são necessárias para a memorização (BUZAN, 2010, p. 120).

Além disso, as anotações tradicionais proporcionam revisões mais demoradas. Perde-se tempo com a leitura de palavras que não têm efeito para a memória e com $\mathrm{o}$ ato de procurar palavras-chave de memorização no texto que, normalmente, não se destacam das demais por nenhuma marcação. O procedimento correto seria resumir informações em palavras-chave estratégicas. $\mathrm{O}$ hábito de escolhê-las corretamente é um processo que precisa de prática.

\subsection{Mapas mentais: sua construção}

Tony Buzan, nascido na Inglaterra em 1942 e graduado em Psicologia, Inglês, Matemática e Ciências, é considerado o pai dos mapas mentais por apresentá-los em seu livro Use yourhead, publicado em 1974, em Londres.

Desde seus tempos na universidade, ele mostrava grande inquietação acerca do funcionamento da mente, sobretudo durante o aprendizado. Diante das constantes avaliações da faculdade, em um contexto em que o costume de estudar baseava-se em anotações, Buzan percebeu que a combinação de várias habilidades (uso de cores e da palavra, por exemplo) permitia que o cérebro funcionasse com maior eficácia. Experimentos consigo próprio e com outras pessoas permitiram o desenvolvimento da técnica (ONTORIA; LUQUE; GÓMEZ, 2006, p. 38).
Nas palavras de Buzan (2010, p. 123), um mapa mental "é uma ferramenta de pensamento interligada gráfica e visualmente para armazenamento, priorização e geração de informações".

É um diagrama que representa uma ideia central da qual partem ramificações, representando informações relacionadas, usando cores, palavras-chave, imagenschave, ritmo, lógica e outros estimuladores da memória.

A significação conceitual que os autores Ontoria, Luque e Gómez dão à técnica é a seguinte:

\begin{abstract}
Os mapas mentais são uma maneira de representar as ideias que se relacionam melhor a símbolos do que a palavras complicadas: a mente forma associações imediatamente e mediante o mapa as representa rapidamente. Habitualmente, os mapas mentais são valorizados como um sistema revolucionário de organização das ideias, uma vez que é um recurso gráfico que integra o uso dos hemisférios, possibilitando ao indivíduo maior capacidade de compreensão. Nesse sentido, o mapa mental converte-se em uma poderosa técnica gráfica que facilita a utilização do potencial cerebral. (ONTORIA; LUQUE; GÓMEZ, 2006, p. 43).
\end{abstract}

A eficácia atribuída aos mapas mentais está relacionada a três características: sua forma, que é uma manifestação direta do conceito de pensamento irradiante; a utilização integrada dos dois hemisférios cerebrais, devido à presença de cores de imagens; e o uso de mnemônicos e palavras-chave.

A Figura 2 é um exemplo simples de mapa mental que representa os conceitos-chave de 7 (sete) páginas de uma apostila da disciplina "Aerodinâmica". Foi confeccionado por um cadete aviador do $3^{\circ}$ ano da AFA.

Figura 2 - Mapa Mental - Aerodinâmica.

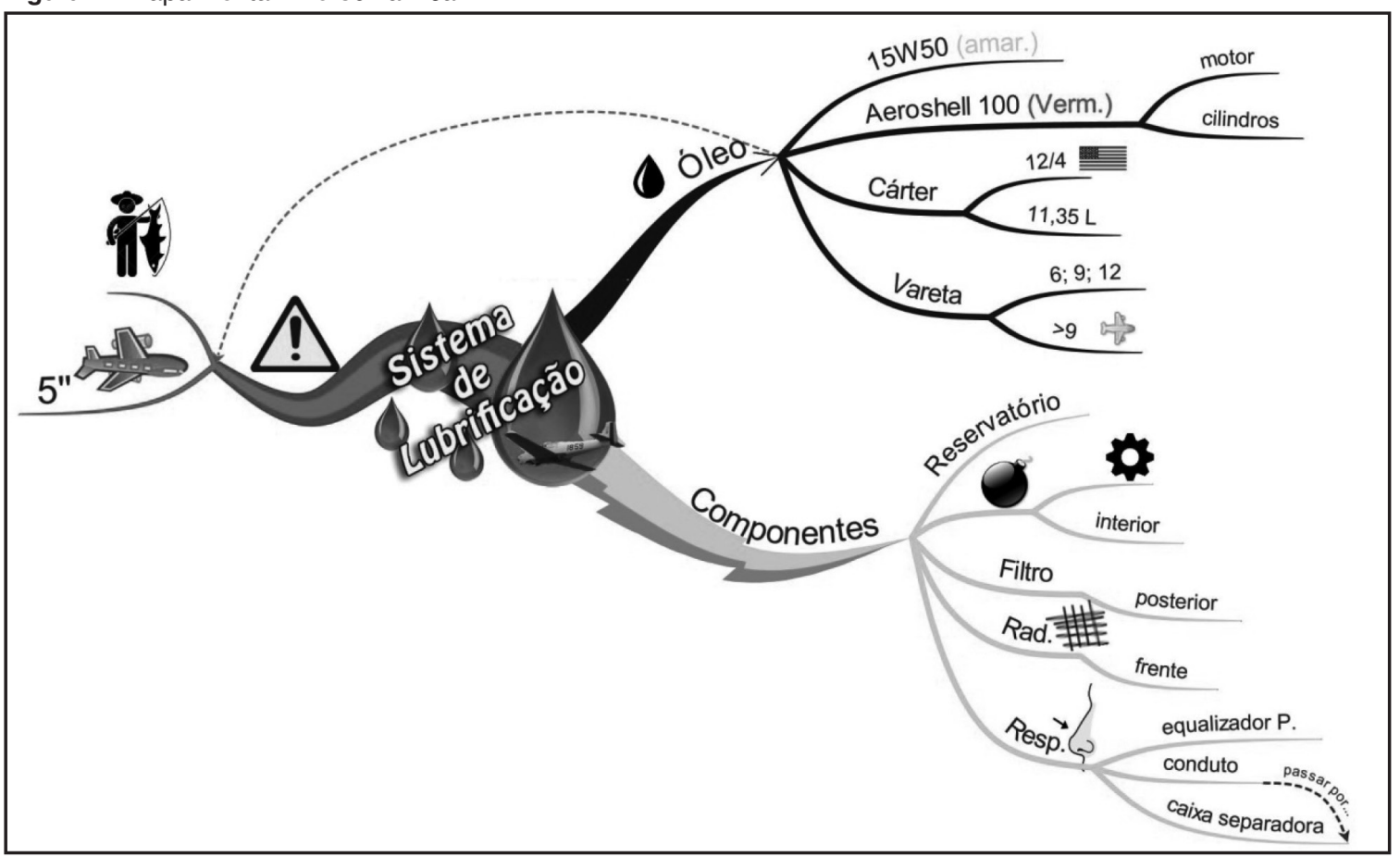

Fonte: $\mathrm{O}$ autor. 
Nota-se, no exemplo (Figura 2) a presença de cores e imagens, o que estimula a atuação do hemisfério cerebral direito e, portanto, o uso do cérebro em sua totalidade. Essa característica corrobora com o que dizem os estudiosos de pedagogia e neurociência sobre o funcionamento da memória:

para que a memória funcione adequadamente no processo de informação, se faz necessária a busca da integração entre os dois hemisférios, equilibrando o uso de nossas potencialidades. (SILVEIRA, 2004).

Outra característica ainda é

[...] de que o cérebro processa melhor, memoriza e relembra mais facilmente informações que combinam palavras, números, ordem e sequência com cores, imagens, dimensões, símbolos e ritmo visual. (FERREIRA; CARVALHO, 2012).

As ideias são reproduzidas por palavras-chave, cuja relevância já foi apresentada. Segundo Galante (2013), o processo de elaboração dos mapas é um dos melhores métodos de estudo, pois obriga o aluno a usar sua capacidade de síntese em ideias essenciais. Elas se ligam umas às outras por meio de ramificações do mapa: uma representação que vai ao encontro do conceito apresentado de "pensamento irradiante", pois as linhas induzem o cérebro a fazer as ligações necessárias.

É o que se afirma no trecho:

O trabalho com mapas mentais potencializa as funções psicológicas superiores, entre elas a memória, [...], por serem modelos que permitem a diagramação do pensamento no formato não linear, assumindo o tipo de estrutura que a memória tem. (FERREIRA; CARVALHO, 2012).

Mas, embora os mapas mentais tenham ganhado milhares de usuários pelo mundo e sejam elogiados por diversos estudiosos, no Brasil ainda é uma ferramenta pouco conhecida por estudantes. Em redes sociais, por exemplo, páginas de estudos baseados em mapas mentais têm poucos frequentadores. Nos blogs e em vídeos da Internet a esse respeito, muitos comentários são de pessoas que não conhecem a técnica e pedem informações de como usá-la.

$\mathrm{Na}$ AFA, esse desconhecimento também é comum. Em pesquisa exploratória realizada com cadetes do $1^{\circ}$ esquadrão, $65 \%$ dos respondentes disseram nunca ter ouvido falar da técnica e 15\% disseram nunca ter usado, embora já tenham ouvido falar.

\section{METODOLOGIA}

\subsection{Metodologias adotadas}

Os procedimentos metodológicos adotados para a confecção deste artigo constituíram-se de pesquisa bibliográfica e pesquisa de campo, realizada com os cadetes aviadores. A descrição, os resultados e as discussões a respeito são expostos nos itens a seguir.

\subsection{Pesquisa de Campo}

Esta pesquisa se deu com a aplicação de um questionário de questões objetivas. O objetivo foi analisar, com as 4 (quatro) primeiras questões, os hábitos de estudos dos cadetes com relação ao voo a ser realizado no ano seguinte e, com as últimas 2 (duas) perguntas, investigar a opinião do pesquisado sobre sua capacidade de memorização e de seu conhecimento acerca da técnica dos mapas mentais.

$\mathrm{Na}$ primeira questão, o respondente teria de indicar o mês em que ele inicia seus estudos para a prova do EIA. Entre 54 (cinquenta e quatro) respondentes, 2 (dois) não responderam a essa pergunta. Entre os que responderam à questão, $73 \%$ iniciam o estudo nos meses de agosto ou setembro (Gráfico 3). Somente 1 (um) cadete (2\%) pretendia iniciar em janeiro, no próprio ano da atividade aérea.

$\mathrm{Na}$ questão seguinte, a segunda, foi perguntado ao cadete se ele pretendia estudar para o voo durante as férias do final do ano. As respostas de 52 (cinquenta e dois) entre 54 (cinquenta e quatro) pesquisados foi positiva e a dos 2 (dois) restantes foi negativa.

$\mathrm{Na}$ terceira questão, solicitou-se que o respondente informasse sua intenção de permanecer no período de férias na AFA para fazer nacele ou viajar para Guaratinguetá ou Lagoa Santa para praticar o exercício. Os resultados foram os mesmos da questão anterior, com 52 (cinquenta e dois) cadetes respondendo "sim" e dois respondendo" não".

Gráfico 3 - Mês de início do estudo para o voo no ano seguinte.

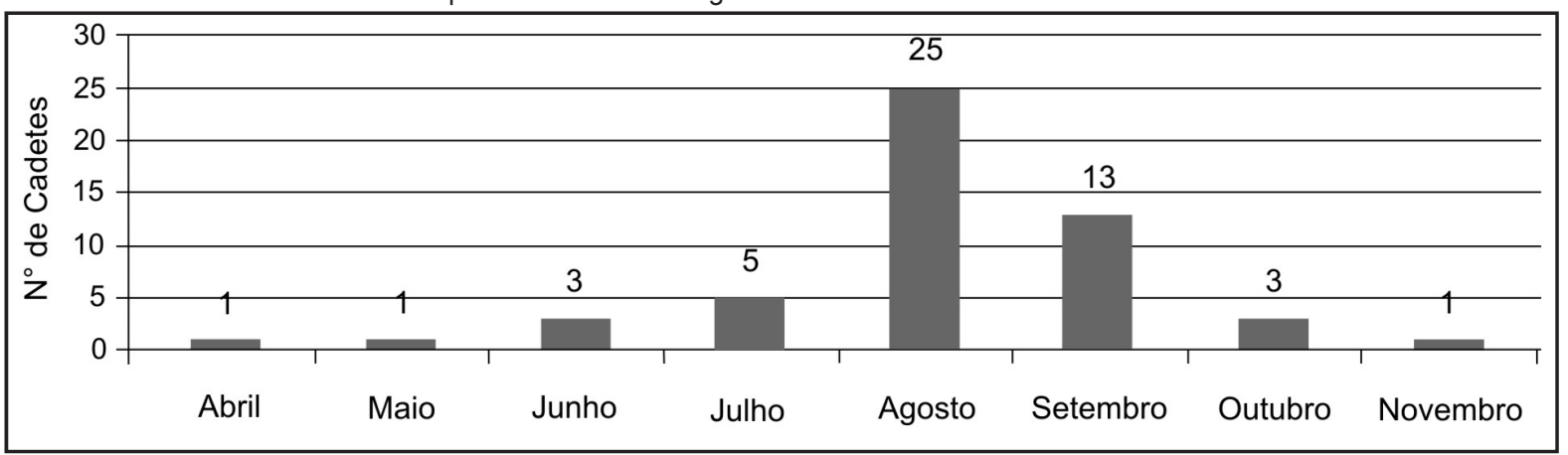

Fonte: $\mathrm{O}$ autor. 
Nota-se que os cadetes percebem, conforme dizem os aviadores de turmas mais antigas, como a cobrança a esse respeito no $2^{\circ}$ EIA é elevadíssima, de modo que sua formação como piloto depende de um bom preparo nesse aspecto.

Com vistas a analisar os hábitos de estudo dos pesquisados, na quarta pergunta, solicitou-se a informação de hábito de estudo para a disciplina MAITE. As indicações assinaladas foram: leituras frequentes, resumos, cópias, discussões/perguntórios com colegas, resolução de questões a respeito e outros (Gráfico 4).

O MAITE foi escolhido como referência por ser o manual mais abrangente e com mais informações a serem memorizadas e, portanto, o que mais se encaixa no uso de mapas mentais.

Os números são de acordo com o que é praticado ano após ano: além da primeira leitura e das óbvias releituras frequentes, a grande maioria dos cadetes costuma fazer resumos, participar de conversas com colegas e resolver questões para testar seus conhecimentos.

A opção de fazer cópias foi marcada por 32\% dos pesquisados. Nenhum cadete assinalou a opção “outros", concluindo-se, portanto, que não há a pretensão de se usar outro método além dos indicados nas alternativas propostas.

Na pergunta seguinte, a quinta, o objetivo foi verificar se é grande a quantidade de cadetes que sentem dificuldade para guardar informações. 10 (dez) pesquisados afirmaram dificuldade ou certa dificuldade para reterem informações, totalizando $19 \%$ da amostra. Apenas 5 (cinco) $(9 \%)$ julgaram ter facilidade. Os 39 (trinta e nove) cadetes restantes $(72 \%)$ marcaram a opção "certa facilidade", interpretada como um desempenho intermediário entre decorar com facilidade e com dificuldade, com leve tendência para a facilidade.

$\mathrm{Na}$ última questão, foi solicitado ao cadete informar seu conhecimento sobre os mapas mentais, uma vez que o objetivo era conhecer o quanto a técnica é difundida dentro do grupo pesquisado.
A maioria de 35 (trinta e cinco) cadetes informou nunca ter ouvido falar de mapas mentais. Esses, somados aos 8 (oito) que afirmaram conhecê-los, apesar de não os praticar, totalizam $80 \%$ dos pesquisados. Entre os que disseram já terem usado há um total de 11 (onze) (20\%).

Embora uma quantidade considerável de respondentes informarem conhecer e já ter usado mapas mentais, a quarta questão indicou que não é intenção de nenhum deles usar essa técnica no estudo para o voo, pelo menos no que se refere ao MAITE.

Defronta-se, portanto, com a viabilidade de esse trabalho apresentar a técnica aos que não a conhecem, como forma de amparar os que não se julgam tão bons nas atividades de memorização, e sugerir seu uso também no estudo de aviação para o $2^{\circ}$ EIA, uma vez que a importância da preparação teórica é de extrema importância para os cadetes.

\section{CONSIDERAÇÕES FINAIS}

Observando-se a rotina acadêmica da AFA, notou-se que a transição entre o $1^{\circ}$ e $2^{\circ}$ ano tem como característica uma grande mobilização dos cadetes aviadores no que se refere ao estudo para o voo do $2^{\circ}$ EIA.

A demanda de muitas informações a serem memorizadas e a estatística relativamente alta de desligamentos fazem com que a maioria dos cadetes inicie com bastante antecedência a preparação teórica e permaneça estudando, inclusive durante as férias do final do ano.

Com o objetivo principal de propor o uso de mapas mentais a cadetes que estão prestes a iniciar a instrução aérea no $2^{\circ}$ EIA, essa discussão partiu das hipóteses de que a técnica estimula a memorização, atendendo, portanto, ao tipo de estudo que a aviação exige, e de que é pouco conhecida pelo grupo de cadetes da AFA.

Gráfico 4 - Meios adotados para o estudo de MAITE.

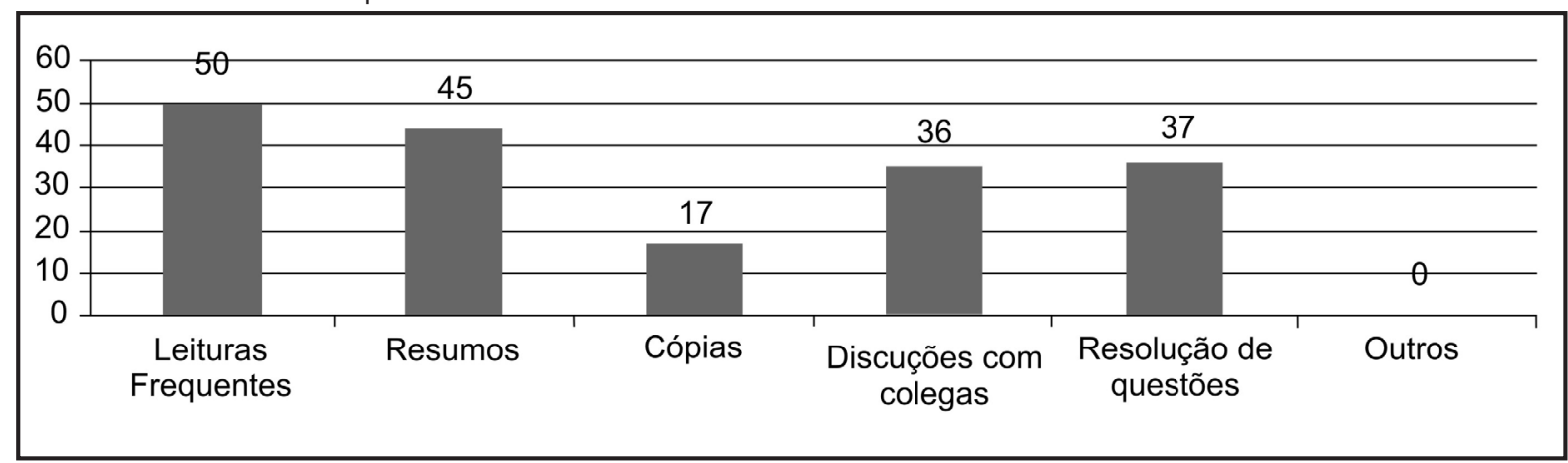

Fonte: $\mathrm{O}$ autor. 
Por meio da pesquisa exploratória, observouse que não é maioria o número de indivíduos que apresentam dificuldades para a memorização, mas é mínima também a quantidade dos que dizem ter plena facilidade em atividades desse aspecto.

As pesquisas bibliográficas permitiram constatar que, como estudos recentes afirmam a potencialidade, ao que parece, ilimitada do cérebro humano, todos têm a capacidade de desenvolver a habilidade de decorar. Sendo assim, conclui-se que, se não há diferenciação entre o potencial cerebral de indivíduos diferentes, o uso da técnica proposta, que estimula o uso holístico da mente, é uma solução cabível para os que estimam ter dificuldades de memorização.

O questionário permitiu observar que, em uma amostra de 54 (cinquenta e quatro) cadetes, a maioria, sequer, nunca ouviu falar de mapas mentais, corroborando a hipótese de que a técnica ainda é desconhecida por muitos investigados.
Verificou-se também que as informações, procedimentos e números que devem ser memorizados, em virtude do aprendizado de MAITE, MAPRO e “checklist", são atendidos pela aplicação dos conceitos de pensamento irradiante, mnemônicos, palavras-chave e uso conjunto dos dois hemisférios cerebrais - expressos pelo uso de mapas mentais.

Dessa forma, o objetivo deste trabalho, em propor a adoção de uma técnica eficiente a um grupo de cadetes que, diante da expectativa e das incertezas referentes ao voo no $2^{\circ}$ EIA, só tem como opção dedicar-se por inteiro aos estudos, foi atingido.

Ademais, os trabalhos dos autores pesquisados permitiram verificar que o uso de mapas mentais permite revisões mais rápidas, o que se encaixa, perfeitamente, às exigências do $2^{\underline{0}}$ EIA, ou seja, ter um aluno bem preparado durante todo o curso de pilotagem.

\section{REFERÊNCIAS}

BRASIL. Comando da Aeronáutica. Departamento de Aviação Civil. Portaria DAC n 954/DGAC, de 27 de agosto de 2004. Aprova a terceira edição do Manual do Curso "Piloto Privado-Avião" (MCA 58-3). Diário Oficial [da República Federativa do Brasil], Brasília, DF, 6 set. 2004. Seção 1, p. 11.

BRASIL. Comando da Aeronáutica. Academia da Força Aérea. Portaria AFA no 19-T/DIV_AFA, de 27 de janeiro de 2014. Aprova a reedição do Programa de Instrução e Manutenção Operacional da Academia da Força Aérea. Boletim Interno Ostensivo [da Academia da Força Aérea], Pirassununga, n. 33, 17 fev. 2014.

Comando da Aeronáutica. Departamento de Ensino da Aeronáutica. Portaria DEPENS no 43/ $\mathrm{DE}-1$, de 31 de janeiro de 2014. Aprova a reedição da Instrução que estabelece o "Plano de Avaliação da Academia da Força Aérea (MCA 37-5). Boletim do Comando da Aeronáutica, Brasília, DF, n. 54, f. 2098, 20 mar. 2014.

FERREIRA, C. P.; CARVALHO, F. A. H. O uso de mapas mentais no ensino técnico para a otimização do perfil empreendedor do profissional do século XI. In: SEMINÁRIO DO CURSO TÉCNICO EM ADMINISTRAÇÃO: ESTUDOS,
REALIDADES E PERSPECTIVAS, 1., 2012, Porto Alegre. Trabalhos apresentados... Porto Alegre: IFSC, 2012. Não paginado.

GALANTE, C. E. S. O uso de mapas conceituais e de mapas mentais como ferramentas pedagógicas no contexto educacional do ensino superior. In: SEMINÁRIO INTERNACIONAL SOBRE A SITUAÇÃO DA POLÍTICA EDUCACIONAL DO MERCOSUL, 2013, Asunción. Anais ... Asunción: [s. n.], 2013.

OLIVEIRA, L. H. As primeiras notícias da década do cérebro. Super Interessante, dez. 1992. Disponível em:< http://super.abril.com.br/ciencia/ as-primeiras-noticias-da-decada-do-cerebro>. Acesso em: 19 ago. 2014.

SILVEIRA, M. M. S. O funcionamento do cérebro no processo de aprendizagem. 2004. Disponível em: <http://www.psicopedagogia.com.br/newl_ opiniao.asp?entrlD=223\#.VkyyNV3d.XGg>. Acesso em: 10 jul. 2014.

VEJA estatísticas de acidentes aéreos no mundo: raios derrubaram aeronaves 15 vezes -- 7 de grande porte. Até agora, 47 acidentes ocorreram em 2009. G1, São Paulo, 4 jun. 2009. Disponível em:< http:// g1.globo.com/Noticias/Mundo/0,,MUL11817845602,00-VEJA+ESTATISTICAS+DE+ACIDENTES+ AEREOS+NO+MUNDO.html>. Acesso em: 10 jul. 2014. 